\title{
Analysis of meteorological and hydrological droughts in the Niger-South Basin, Nigeria
}

\begin{abstract}
Information gained from drought analysis can serve as the basis for water resources planning and management under the prevailing climate change condition especially at the basin scale. The aim of this work is to apply two meteorological drought indices - Standardized Precipitation Index (SPI), Standardized Precipitation Evapotranspiration Index (SPEI) and a hydrological drought index - Standardized Runoff Index (SRI) to investigate the occurrence of drought in the Niger-South Basin (NSB), a sub-catchment of the Niger River Basin in Nigeria, during the period 1970-2008. The results showed that the period between 1970 and 1981 was dominated by wet conditions; second, from 1982 to 1998, a period of droughts ranging from moderate dry to extreme dry alternated with moderate wet conditions, while the third period beginning from 1999 to 2008 displayed another round of severe droughts sparingly intercepted by occasional moderate wet conditions. High correlation values of between 0.66 (at 3-month scale) and 0.56 (at 12-month scale) show comparativeness in the performance of the two drought indices. For the hydrological drought, a severe drought was observed in 1982 and near normal and moderately wet since 1997. The higher agreement between the SRI and SPEI, suggests that hydrological droughts are more affected by temperature (warming) than precipitation (drying) in the basin. Further analysis of the frequency of the various conditions shows that it has been more of near normal conditions (> $60 \%$ ), while extremely dry and wet conditions ( $2 \%$ each) have been very rare. However, given the projected global warming conditions, a reversal of the present normal condition might be witnessed in the nearest future, hence, the results of this study can serve as a basis for effective water resources planning and management in the basin.
\end{abstract}

Keyword: Droughts; Normal condition; Extremely wet; Extremely dry; Niger-South Basin 